\title{
A Generalized Learning Curve Adapted for Purchasing and Cost Reduction Negotiations
}

\author{
Lam F. Wong \\ Department of Engineering \& Engineering Technology, Cuyahoga Community College, MHCS 122, 2900 Community College Avenve, \\ Cleveland, OH 44115-3196, USA \\ Correspondence should be addressed to Lam F. Wong; lam.wong@tri-c.edu
}

Received 4 October 2012; Accepted 11 December 2012

Academic Editor: Ching-Jong Liao

Copyright (C) 2013 Lam F. Wong. This is an open access article distributed under the Creative Commons Attribution License, which permits unrestricted use, distribution, and reproduction in any medium, provided the original work is properly cited.

\begin{abstract}
This paper presents the use and validation of a generalized learning curve in the economies of scale purchasing experience. The model, based on Wright's curve, incorporates two extra degrees of freedom to accommodate initial purchases of multiple (instead of single) units and a finite asymptotic price at high volumes. The study shows that each time the part purchase quantity is doubled, the price is reduced either by a constant percentage (a learning rate) or by an approach to an asymptotic plateau rate indicating a point of diminishing returns. Supplier price quotations at multiple purchase quantities were obtained for a pool of $17 \mathrm{critical} \mathrm{parts.}$ The data were fitted with the generalized learning curve by the method of least squares regression. The regressed learning rate, first unit price, and the asymptotic price can be used to infer supplier pricing strategies. Coupled with a "should-cost" analysis based on estimates of standard time and material, a system cost reduction task was carried out by the supply chain organization.
\end{abstract}

\section{Introduction}

One of the challenges in a supply chain function is to carry out win-win negotiations with suppliers for part quality, cost, and delivery. Part quality is essential and should not be negotiable, provided that the specification is sound. A well-written specification with measurable attributes and well-defined statistical requirements will provide a precise quality foundation. Just-in-time (JIT) part delivery schedule would be ideal. However, some inventories of parts may help to ensure the continuity of supplies during abnormal circumstances. In the case of critical parts, the company may want to source them from more than one supplier. Tradeoff analysis must be conducted judiciously with multiple supplier sourcing strategy since it usually works against the part cost.

Here is a brief description of a cost reduction strategy used in a fuel cell company. A Wright-based learning curve was used to determine the economic order quantity and to aid in the negotiation of the lowest possible, but fair, part price. A win-win negotiation strategy can build upon openness and trust. However, doing the homework upfront will go a long way in the negotiation process. Competitive benchmarking of suppliers is an important step to narrow down the list of potential suppliers. Should-cost analysis should be carried out on $20 \%$ of parts that make up $80 \%$ of the system cost. The analysis takes into account the production method, the amount of material used, the various processing times, and the estimated profits. While this analysis may provide a good understanding of the variable costs, the fixed costs may vary widely among suppliers. A typical classification between variable and fixed costs is shown in Table 1.

Not all variable costs have exactly the same meaning. Some variable costs behave in a true variable or proportionately variable fashion. Other variable costs behave in a stepvariable fashion. The same can be said about the fixed and quasifixed costs. For simplicity, part costs shall be classified as either variable or fixed from here on in this paper.

The objectives of this paper are organized primarily as follows: (1) a literature review of the relevant learning curves is discussed because they have been used extensively in the past to model the simple concept known as the economies of scale; (2) a generalized learning curve model adapted for purchasing and cost reduction negotiations is introduced; the model is then used to fit supplier quotations of parts through a least squares percent error method; the results are used to shed light on the supplier pricing strategies and 
TABLE 1: Cost classification.

\begin{tabular}{|c|c|c|}
\hline Cost item & Category & Description \\
\hline Direct material cost & Variable & $\begin{array}{l}\text { The materials (parts, and subsystems) that go into the final } \\
\text { product }\end{array}$ \\
\hline Direct labor cost & Variable & Constant productivity of people directly involved in production \\
\hline Energy & Variable & Used primarily for production \\
\hline SAG & Variable & Selling, administrative, and general costs \\
\hline Commissions & Variable & Usually proportional to the quantity of goods sold \\
\hline Shipping & Variable & $\begin{array}{l}\text { Sometimes, a portion with the supplier and a portion with the } \\
\text { buyer }\end{array}$ \\
\hline $\mathrm{R} \& \mathrm{D}$ & Fixed & Research and development tasks \\
\hline Fixed cost & Fixed & $\begin{array}{l}\text { Amortization of capital goods, rent, depreciation of buildings } \\
\text { and equipment, taxes on real estate, insurance, salaries of top } \\
\text { management and operating personnel }\end{array}$ \\
\hline Discretionary fixed & Fixed & $\begin{array}{l}\text { Advertising, public relations, management development } \\
\text { programs }\end{array}$ \\
\hline IP acquisition cost & Quasi-fixed & $\begin{array}{l}\text { Intellectual property design cost, licensing agreement, and } \\
\text { royalty payment }\end{array}$ \\
\hline Manufacturing overhead cost & Quasi-fixed & $\begin{array}{l}\text { Maintenance and repairs on production equipment, heat and } \\
\text { light, and depreciation }\end{array}$ \\
\hline Indirect labor & Quasi-fixed & $\begin{array}{l}\text { Discrete jump will happen when the overall scale of production } \\
\text { drastically changes. }\end{array}$ \\
\hline Profits & Quasi-fixed & Depending on pricing strategies \\
\hline
\end{tabular}

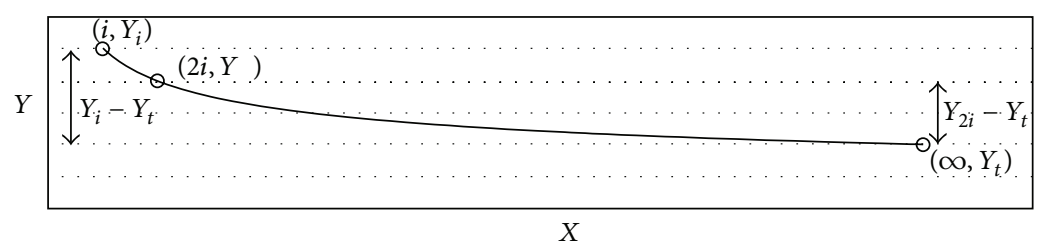

FIgURE 1: The power curve model of $Y$ as a function of $X$.

cost reduction negotiations; and (3) finally, the purchasing experience and cost reduction results are discussed.

\section{Literature Review}

Learning curves have been around since the early 1900s and have been used to model productivity or efficiency improvement based on learning experience. Some forty different equations on published learning curves were reviewed by Thurstone [1] for consideration in his typewriter typing experiment. He selected ultimately the hyperbolic form of learning curve as follows to fit his data;

$$
Y=\frac{L(X+P)}{(X+P)+R},
$$

where $Y=$ typing speed, $X=$ pages typed in the past, $L=$ limit, $P=$ equivalent previous practice and $R=$ rate of learning.

The hyperbolic model fits well with his empirical experiment. He concluded that typewriter learning increases with practice and attains an upper limit quickly. The meaning for the rate of learning in his model is simply a dimensional model coefficient and is not nearly as meaningful as the dimensionless rate in Wright's [2] curve. Furthermore, the hyperbolic model does not fit well with slow learning processes.

Another common form to capture the learning effect is the exponential decay model. In their modeling work of a production-inventory study, Das et al. [3] took into account the efficiency gain in production and setup costs to maximize the expected profit. Two coefficients, one for product cost and one for setup cost, were used in the learning effect. Discussions of the learning coefficients were limited since their effort focused on using the genetic algorithm for a fuzzy simulation.

Wright studied the variation of cost with quantity since 1922 and described a basic theory for obtaining cost estimates based on repetitive production of airplane assemblies. His curve was derived empirically based on previous production experience. Although Wright did not name his curve and the word "learning" never appeared in his paper, somehow his curve became widely known as the learning curve.

The theory of learning is simple. It is recognized that repetition of the same operation results in less time or effort expended on that operation. For the Wright learning curve, the underlying hypothesis is that the direct labor man-hours 


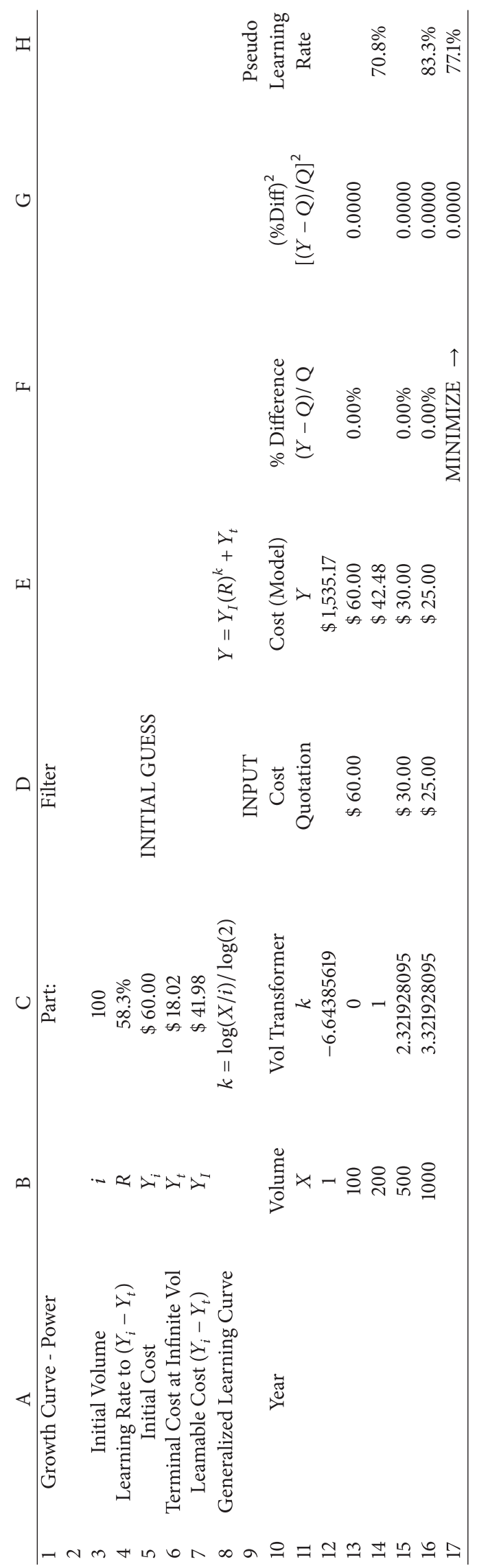

FIGURE 2: Model summary for filter. 
necessary to complete a unit of production will decrease by a constant percentage each time the production quantity is doubled. Wright's learning curve is a simple power model and can be interpreted as

$$
F=N^{(-\log (r) / \log (2))}
$$

where $N=$ production quantity, $r=$ learning rate, and $F=$ a factor equal to the first unit cost divided by the average cost of the $N$ units.

Typical learning rates range between 70 and 95\% for manufacturing and procurement activities. Accordingly, each time the volume doubles, the cost is reduced by 30 to $5 \%$ (i.e., $100 \%$ minus the learning rate). As the production quantity $(N)$ approaches a very large number, the average cost for each of the $N$ units diminishes. The Wright learning curve has wide applications in startup situations, where $N$ is small.

In light of the law of diminishing returns, a factor of incompressibility was added to the power model by DeJong [4] to extend the learning curve model from start-up to steady-state conditions. The model was used to express the impact of the effects of increasing skill on cycle time performance and had the form of

$$
T_{s}=T_{1}\left[M+(1-M) S^{-m}\right],
$$

where $T_{1}=$ cycle time required for the first product, $T_{s}=$ cycle time required for the $S$ th product, $S=$ sequence number, $M=$ incompressibility factor, $0 \leq M \leq 1 \mathrm{~m}=$ exponent of reduction, and $0<m<1$.

In the case where the incompressibility factor is zero, DeJong's model reverts back to the Wright learning curve. DeJong found that the incompressibility factor was about 0.25 in assembly operations, and it increased (less learning) as tasks became more uniform. In his study, the exponent of reduction stayed at 0.32 corresponding to a learning rate of $80 \%$.

Over the years, variants of Wright's learning curve and applications have been reported widely in many industries and disciplines. Here are examples on the selected few of them. Globerson and Gold. [5] treated learning as a stochastic process and derived statistical expressions to predict the range of future performance. Jaber [6] provided a comprehensive review of various learning curve models and discussed both the learning and forgetting phenomena.

Kara and Kayis [7] examined five learning curve models along with simulation to estimate iteration cycles and project completion time in concurrent engineering projects. Kull et al. [8] compared four learning models and validated various forms of power-law learning for the online web-based ordering experience. Gunawan [9] found learning rate to be $96 \%$ in sheet metal lean manufacturing operations. Boone and Ganeshan [10] and Liao [11] examined productivity and performance improvements in service organizations.

Nemet [12] found weak correlation between experience learning and cost reductions in photovoltaic modules; plant size and module efficiency had a stronger effect on cost reductions. On the contrary, Lieberman [13] found a strong and consistent learning effect on pricing in the chemical processing industries based on data from 37 chemical products.

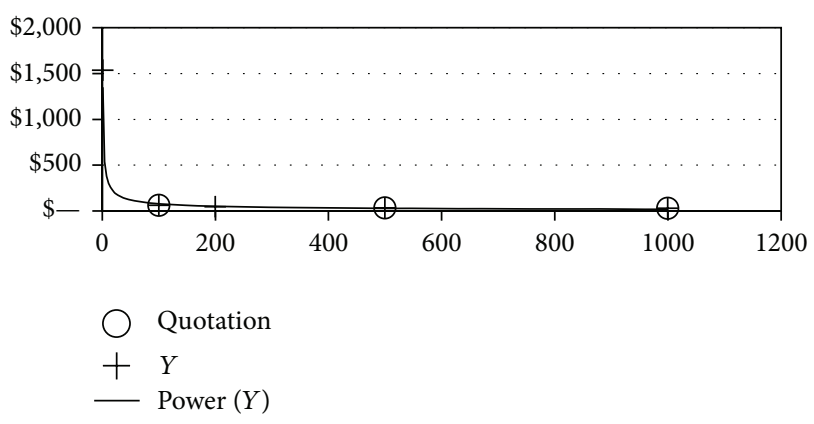

FIGURE 3: Graph of quotation price versus learning model price for filter.

Sinclair [14], using cost data for 221 products from a specialty chemicals business unit, showed a learning rate of $88 \%$ for purchasing of raw materials as compared to a learning rate of only $97 \%$ from manufacturing of the products.

\section{Generalized Learning Curve}

After 76 years of examination since Wright [2] introduced the concept, the term "learning curve" is synonymous with a constant percentage improvement of an objective function whenever the activity or effort is doubled. Using this postulation, let us revisit the learning curve in the generalized exhibit as shown in Figure 1.

The equation based on this foundational concept is simply

$$
Y_{2 i}-Y_{t}=\left(Y_{i}-Y_{t}\right) R
$$

where $Y_{i}=$ initial value of an objective function at $X$ equals to $i, Y_{2 i}=$ value of the objective function at $X$ equals to $2 i$, $Y_{t}=$ terminal value of the objective function as $X$ approaches infinity, $R=$ learning rate, and $X=$ activity level, which will be generalized later.

The activity level " $X$ " is not shown earlier in (4) so that the concept of an initial activity level variable " $i$ " can be introduced first. The term " $Y_{i}-Y_{t}$ " can be viewed as the "learnable" portion of the total performance value that can be "learned away" after a substantially large activity. The terminal value also known as the asymptotical value can either be finite or zero. By doubling the activity once, and then again, the learning rate compounds twice and three times as follows;

$$
\begin{aligned}
& Y_{4 i}-Y_{t}=\left(Y_{i}-Y_{t}\right) R^{2}, \\
& Y_{8 i}-Y_{t}=\left(Y_{i}-Y_{t}\right) R^{3} .
\end{aligned}
$$

The general form of the equation with " $n$ " doublings becomes

$$
Y_{2^{n} i}-Y_{t}=\left(Y_{i}-Y_{t}\right) R^{n}
$$

To generalize by letting $x=2^{n} i$, then it can be shown that $n=\log (x / i) / \log 2$. 


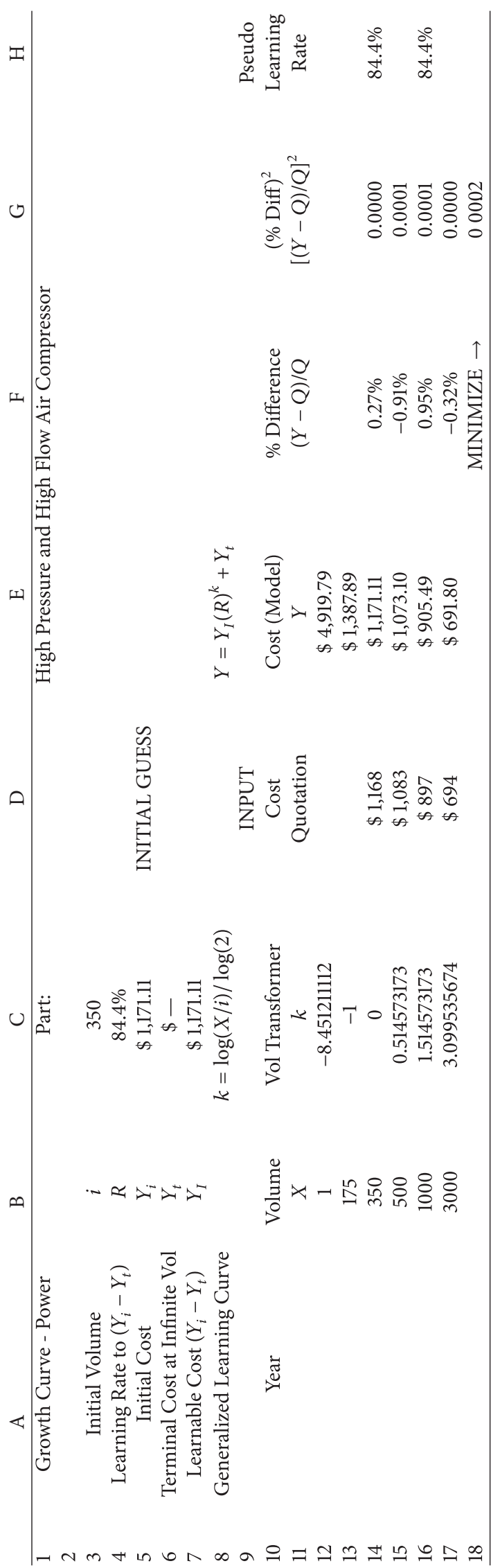

Figure 4: Model summary for air compressor. 
Equation (6) becomes

$$
\begin{aligned}
& Y_{x}-Y_{t}=\left(Y_{i}-Y_{t}\right) R^{\log (x / i) / \log 2}, \\
& Y_{x}=Y_{t}+\left(Y_{i}-Y_{t}\right) R^{\log (x / i) / \log 2} .
\end{aligned}
$$

In a more conventional form, the generalized learning curve becomes

$$
Y_{x}=Y_{t}+\left(Y_{i}-Y_{t}\right)\left(\frac{x}{i}\right)^{\log R / \log 2},
$$

where $x=$ activity level, the independent variable, $i=$ initial activity level, and $Y_{x}=$ performance value at $x$ activity level.

The generalized learning curve, (9) (or (8)), maintains the basic simplicity of the power curve and can be used for any value of the initial activity level and terminal performance value. In case " $i$ " is equal to one, (9) is equivalent to the DeJong model. And additionally if " $Y_{t}$ " is equal to zero, (9) is the same as Wright Theodore's learning curve model.

\section{Application}

In a similar effort as documented by Sinclair [14], the task was to reduce the cost of a product without changing the design. It became clear that any savings would have to come from the purchasing of parts and assemblies, not from basic product design. Existing supplier agreements posed an added challenge because many parts were under contract for the previously agreed on price. The only avenue of opportunity came from the revised marketing forecast, which predicted a $40 \%$ increase in initial product demand. This led to the increase of parts' purchasing quantity.

It was prudent to work with existing suppliers on critical parts and, if necessary, to develop low cost suppliers on noncritical parts. Suppliers were requested to provide quotations on part pricing at three or four quantities of purchase. Concurrently, should-cost analysis of parts was conducted to somewhat validate the quotations. An experienced supply chain group would determine the price versus volume data and would fit them to the generalized learning curve model by regression using the least square fit of the percent errors. In this way, negotiations would be based on analytical insights, and cost-pricing relationships could be established.

The coefficients of each part model provided a "directional" estimate of the fixed cost $\left(Y_{i}-Y_{t}\right)$, variable cost $\left(Y_{t}\right)$, and the learning rate $(R)$. The estimated variable cost was compared to the should-cost analysis. The estimated learning rate was compared to the $85-88 \%$ guideline for purchased parts published by Stewart et al. [15]. Furthermore, parts were categorized into the following three groups: component off the shelf COTS, minor modification of COTS, and custom designed parts

If the part was a COTS, we further estimated the percentage of our purchase with respect to the production volume of the supplier to understand leverage. Custom designed parts are unique and have huge learning potentials. Based on the previous comparisons and part classifications, a pricing strategy for each part was relegated to one of the four likely standards: cost-plus pricing, target return pricing, valuebased pricing, and psychological pricing. Supplier visits and negotiations were conducted with a majority of the existing/new and with/without contract in place suppliers.

\section{Results and Discussion}

The generalized learning curve model was coded in an MS Excel spreadsheet. The built-in "solver" function was used to perform a least square regression fit. Three examples have been selected for discussions. Figure 2 shows the basic structure of the model programmed using the equivalent equation (8) (as opposed to (9)). The independent variable " $X$ " is the part purchase quantity or volume. The dependent variable " $Y$ " is the part price (or cost to the company) per unit at the corresponding volume.

The inputs are the supplier quotations at three volumecost pairs. In this case, the initial volume (cell C3) is 100 pieces of a filter. The primary outputs (the initial guess box) are the learning rate, model-calculated initial cost, and the terminal cost. It should be noted that the learning rate (cell C4) applies only to the learnable portion of the cost. The learnable portion does not include the terminal cost, which can be finite or zero.

The calculated pseudolearning rates (column $\mathrm{H}$ ), which are based on the ratio of absolute costs, trend to a plateau effect at higher volumes. By definition, the learning rate is supposed to stay constant at each doubling of volume. However, with a nonzero terminal cost, the prefix "pseudo" is added to represent a learning rate that is changing with each volume doubling. The average for the pseudo-learning rate $(\mathrm{H} 17)$ calculated within the quoted volume range may be used for comparison in the absence of the constant learning rate. The backward projected cost for the first unit (cell E12) is also calculated using the learning curve model.

With only three volume-cost input pairs, the regression may give a perfect fit as in this case. The supplier quotation price (or purchaser cost) versus the model cost and the general learning curve shape are plotted in Figure 3. The pricing strategy for this filter part appears to be the cost-plus pricing type because the terminal cost (cell C6) seems to be in line with the variable cost. In general, the learnable cost (cell C7) can be viewed as the fixed cost for the part. The high first unit cost (cell E12) may be implicated by setup charges or business development expenses.

The least square regression fit algorithm is quite robust using just the default regression fit parameters. Convergence to the best fit may take up to three iterations by inputting initial guess with common sense that the learning rate is between 50 and 99\%, and the initial cost is higher than the terminal cost. These three values from the initial guess will be written over automatically after each iteration. Most of the time, convergence takes only one iteration.

The second example is an air compressor part shown in Figures 4 and 5. This time, there are four quotation pair points preventing the possibility of a perfect fit. The maximum regression error (column $\mathrm{F}$ ) at any price point is less than $1 \%$, which is quite typical based on experience with many pricing examples. The fitted terminal cost is zero, which implies no plateau effect. Consequently, the learning rate and the pseudo-learning rates are one and the same. The air compressor is a custom design with an intricate 
TABLE 2: Learning rate of parts with no plateau.

\begin{tabular}{lcc}
\hline Item no. & Purchase part name & Learning rate \\
\hline 1 & Pressure sensor & $84 \%$ \\
2 & Air compressor & $84 \%$ \\
3 & Current sensor & $88 \%$ \\
4 & Gas sensor & $90 \%$ \\
5 & Ultracapacitor module & $93 \%$ \\
6 & Inductor & $94 \%$ \\
7 & Ultracapacitor assembly & $94 \%$ \\
8 & Air mass flow sensor Assembly & $96 \%$ \\
9 & NiMH battery (supplier A) & $98 \%$ \\
10 & High power NiMH battery & $98 \%$ \\
\hline & Average & $92 \%$ \\
\hline
\end{tabular}

TABLE 3: Average pseudo learning rate of parts with plateau.

\begin{tabular}{lcc}
\hline Item no. & Purchase part name & Learning rate \\
\hline 1 & T-fitting assembly & $74 \%$ \\
2 & Filter & $77 \%$ \\
3 & Radiator fan & $92 \%$ \\
4 & Li-ion battery & $92 \%$ \\
5 & Air filter & $93 \%$ \\
6 & Tracking regulator & $95 \%$ \\
7 & NiMH battery (supplier B) & $99 \%$ \\
\hline
\end{tabular}

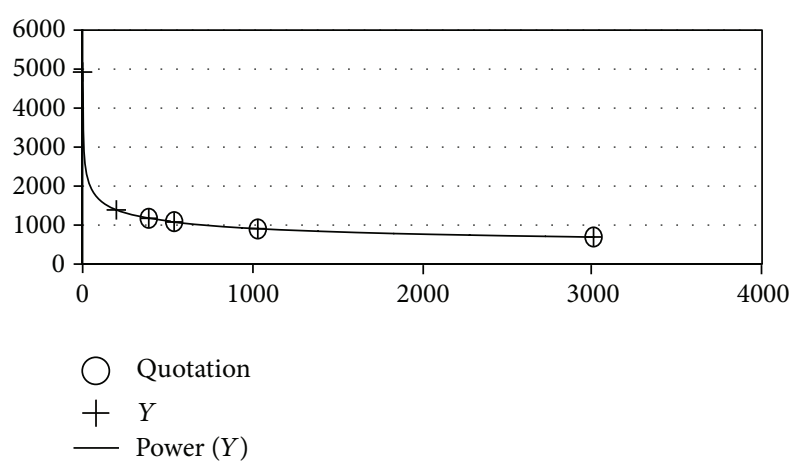

FIGURE 5: Graph of quotation price versus learning model price for air compressor.

assembly procedure. Based on the information gathered from a supplier visit and diminishing variable cost from the regression model, the pricing strategy for the air compressor appears to be a target return pricing type.

The last example is a pressure sensor shown in Figures 6 and 7. The sensor example was selected because it gives the largest percent (fit) error, a little over 6\%, from a pool of 17 critical parts. The fitted terminal cost is also zero, so the learning rate is the same as the pseudo-learning rates. The regressed first unit price is reasonable, and the learning rate is one of the relative best. It is a COTS item with an apparent value-based pricing strategy.

Of the 17 regression analyses, 10 parts have a zero terminal cost. Their learning rates are shown in Table 2 . The range from best to worst goes from 84 to $98 \%$ with an average of $92 \%$. The learning rates of the other seven parts are not as meaningful because of the plateau effect as discussed earlier. However, for comparison, the average pseudo-learning rates were calculated as shown in Table 3. These learning curve ranges are wider than the published range of 85 to $88 \%$ for purchased parts (Stewart et al., [15]). While the published range is slightly outdated because of the automation advancements, it nevertheless provided the basis for price negotiations with suppliers. Automation has been shown to reduce the amount of learning possibility.

\section{Conclusions}

It is evident that the learning curve is a helpful tool for part purchasing negotiations. In most cases, the curve fits well with the supplier pricing quotations, assuming the fixed and variable costs dominated. In the case where the fit is not as smooth, it could be caused by the quasifixed cost or step variable cost in the supplier pricing analysis.

The generalized learning curve provides two extra degrees of freedom to handle the initial purchase quantity variation and the law of diminishing return issue. The regression gives the first unit cost and the terminal cost, which can be viewed as the total (fixed plus the variable) cost, and the variable cost, respectively. Normally, it is not a good idea to extrapolate to the two ends significantly beyond the supplier quotation range. This concern is supported by 10 out of 17 parts that have a zero terminal value, a surrogate for the variable cost. Nevertheless, the insights extracted are valuable. 


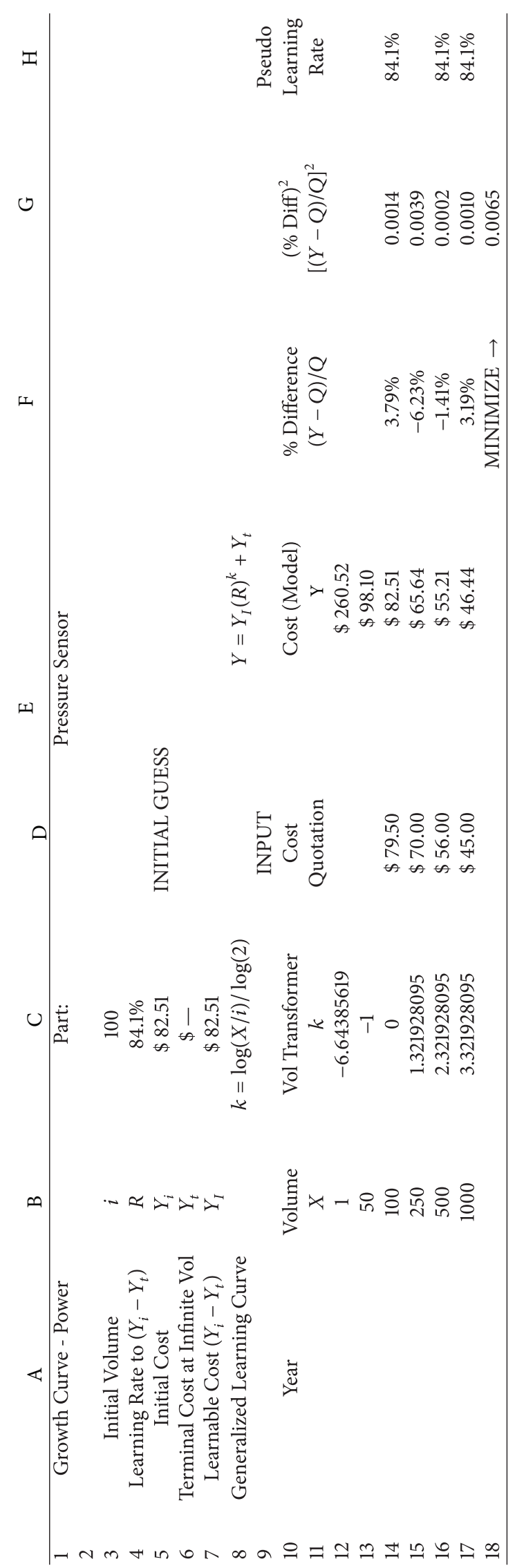

FIGURE 6: Model summary for pressure sensor. 


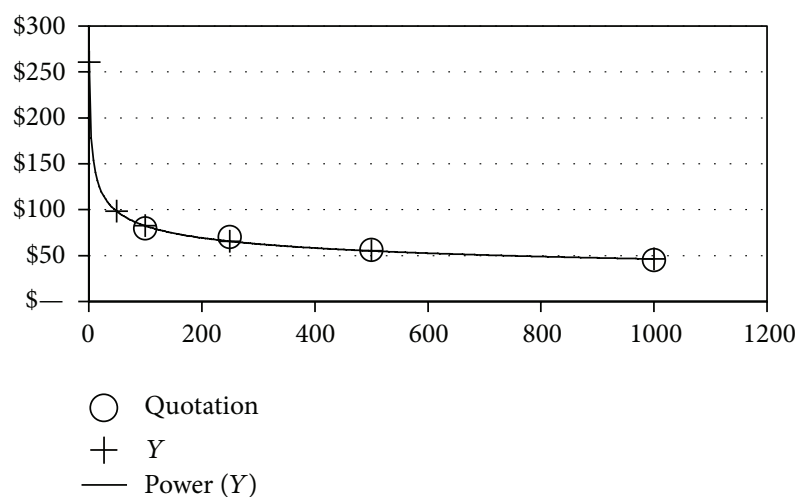

FIGURE 7: Graph of quotation price versus learning model price for pressure sensor.

Early on with the company, almost all supplier quotations were single point in nature for JIT purchases. Price elasticity of parts was not apparent, which made negotiations contentious and difficult. By doing the essential cost and elasticity study upfront, negotiations can become win-win for both parties. The supplier can win by openly discussing cost saving measures and potential business opportunities, such as gainsharing.

The practice of lean manufacturing has been proven to be a crucial competitive advantage. The lean supply chain is a newer concept. Companies need to share information and coordinate demand forecasts, production planning, and inventory replenishment with suppliers. Progressive companies strive to build a highly collaborative business environment and may want to consult with their suppliers on business best practices.

Additionally, lean means doing one's own homework and minimizing the nonvalue added burdens on the suppliers. Very often and truly believing "the customer is always right," companies can place unreasonable demands on suppliers resulting in unnecessary (throw away) activities. The erosion of supplier profit margins may negate any potential for cost reduction negotiations.

With a "lean supply chain" approach, like the work documented in this paper, promise for a win-win approach in purchasing relationships is clearly feasible. One supplier was willing to drop the price of a part by $50 \%$ with a small packaging change. Many suppliers reduced their price to be on par with a should-cost analysis and/or with published learning rates. Yet, there were some suppliers who would not budge due partially to being the only game in town, financial demands (returns), or corporate culture. Overall, a $20 \%$ system cost reduction, purely through "purchasing," was achieved for a fuel cell product in production.

\section{References}

[1] Louis L. Thurstone, “The learning curve equation,” Psychological Monographs, vol. 26, 114 pages, 1919.

[2] Theodore P. Wright, "Factors affecting the cost of airplanes," Journal of Aeronautical Sciences, vol. 3, no. 4, pp. 122-128, 1936.
[3] D. Das, A. Roy, and S. Kar, "A production-inventory model for a deteriorating item incorporating learning effect using genetic algorithm," Advances in Operations Research, vol. 2010, Article ID 146042, 26 pages, 2010.

[4] J. R. DeJong, "The effect of increased skills on cycle time and its consequences for time standards," Ergonomics, vol. 1, pp. 51-60, 1957.

[5] S. Globerson and D. Gold, "Statistical attributes of the power learning curve model," International Journal of Production Research, vol. 35, no. 3, pp. 699-711, 1997.

[6] Mohamad Y. Jaber, "Learning and forgetting models and their applications," in Handbook of Industrial and Systems Engineering (Industrial Innovation), chapter 30, Taylor \& Francis, 2006.

[7] S. Kara and B. Kayis, "The effect of the learning process in concurrent engineering projects," Concurrent Engineering Research and Applications, vol. 13, no. 3, pp. 209-217, 2005.

[8] T. J. Kull, K. Boyer, and R. Calantone, "Last-mile supply chain efficiency: an analysis of learning curves in online ordering," International Journal of Operations and Production Management, vol. 27, no. 4, pp. 409-434, 2007.

[9] I. Gunawan, "Implementation of lean manufacturing through learning curve modelling for labour forecast," International Journal of Mechanical \& Mechatronics Engineering, vol. 9, no. 10, 2009.

[10] T. Boone and R. Ganeshan, "The effect of information technology on learning in professional service organizations," Journal of Operations Management, vol. 19, no. 4, pp. 485-495, 2001.

[11] C.-N. Liao, "Estimate guarantee service costs using learning curve model: a watch chain store empirical study," ProbStat Forum, vol. 2, pp. 31-39, 2009.

[12] G. F. Nemet, "Beyond the learning curve: factors influencing cost reductions in photovoltaics," Energy Policy, vol. 34, no. 17, pp. 3218-3232, 2006.

[13] M. B. Lieberman, "The learning curve and pricing in the chemical processing industries," Rand Journal of Economics, vol. 15, no. 2, pp. 213-228, 1984

[14] G. Sinclair, "Purchasing and the learning curve: a case study of a specialty chemicals business unit," Journal of Supply Chain Management, vol. 35, no. 2, pp. 44-49, 1999.

[15] R. D. Stewart, M. W. Richard, and J. D. Johannes, Eds., Cost Estimator's Reference Manual, John Wiley \& Sons, 2nd edition, 1995. 


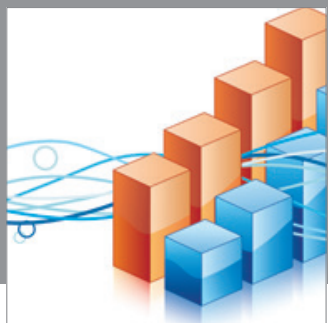

Advances in

Operations Research

mansans

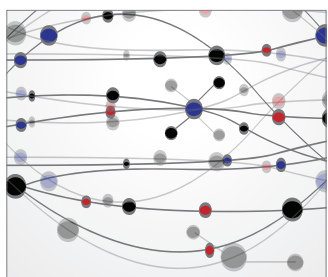

The Scientific World Journal
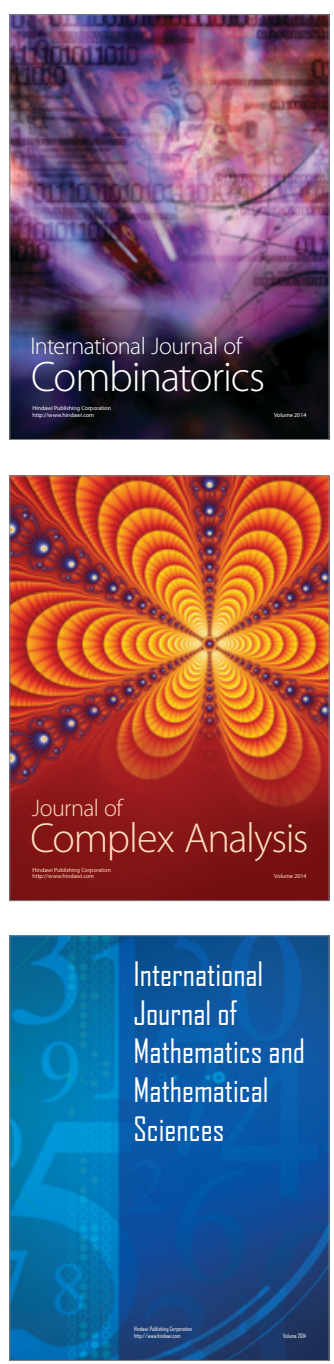
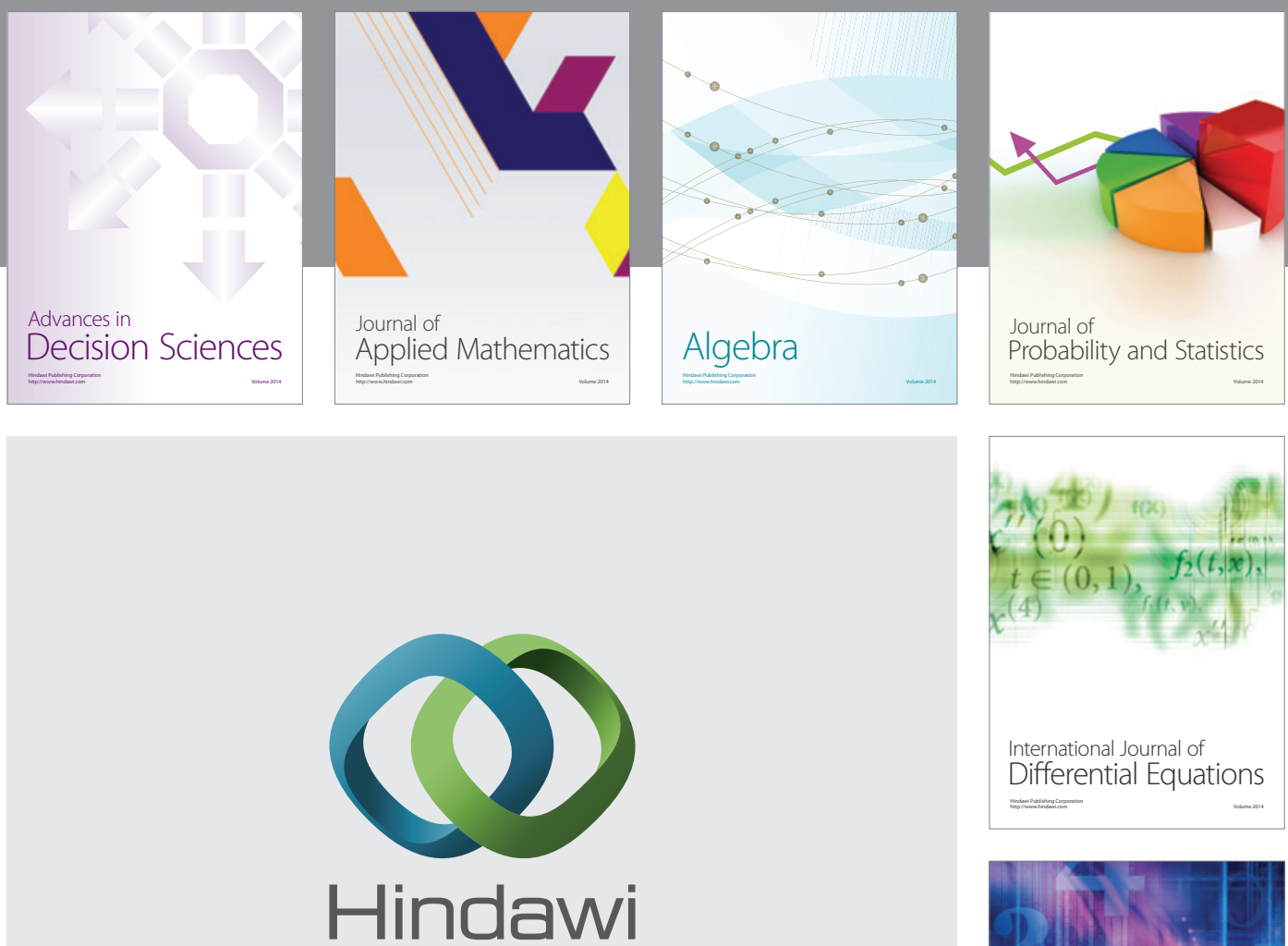

Submit your manuscripts at http://www.hindawi.com
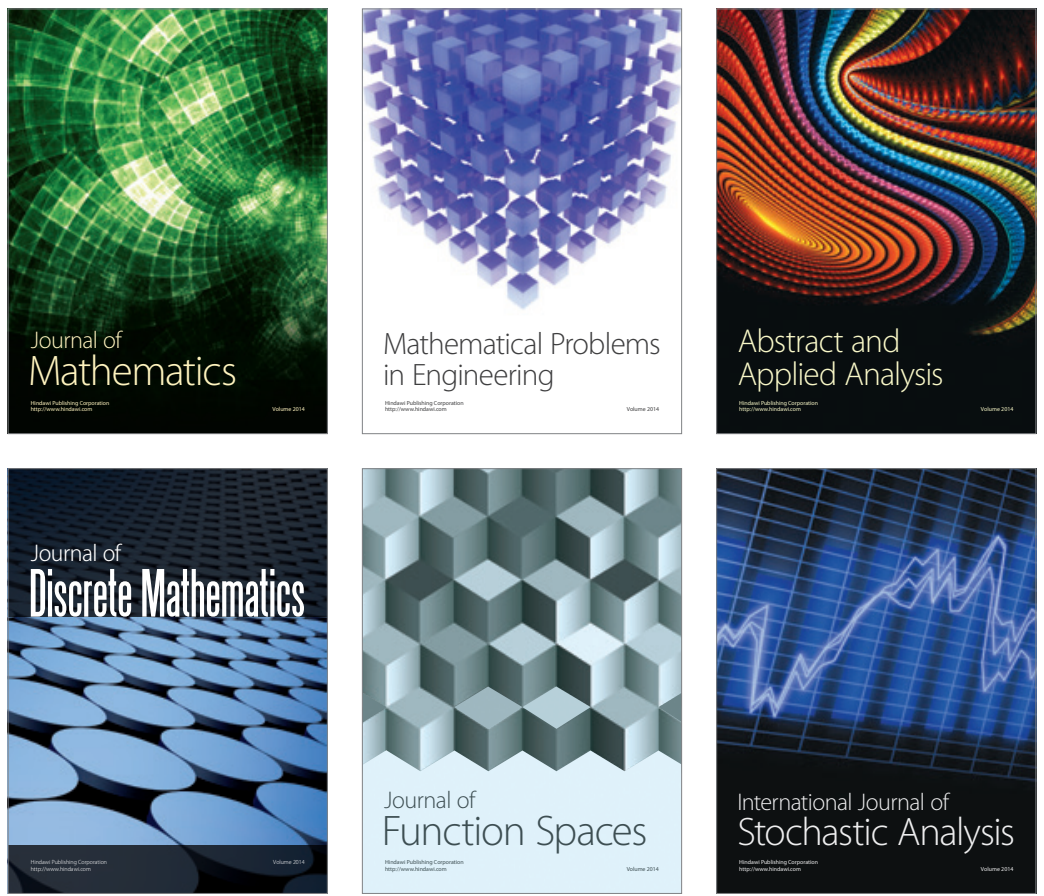

Journal of

Function Spaces

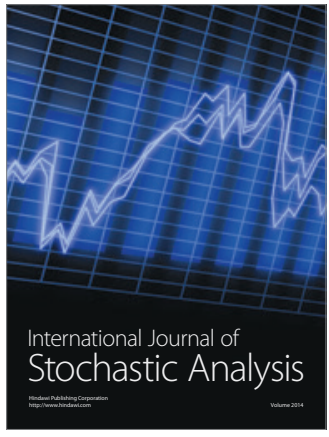

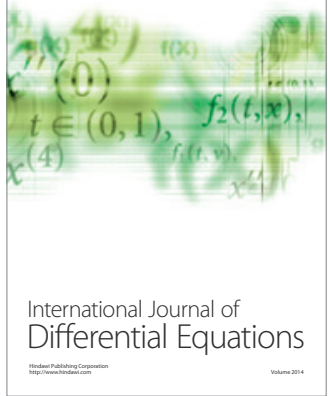
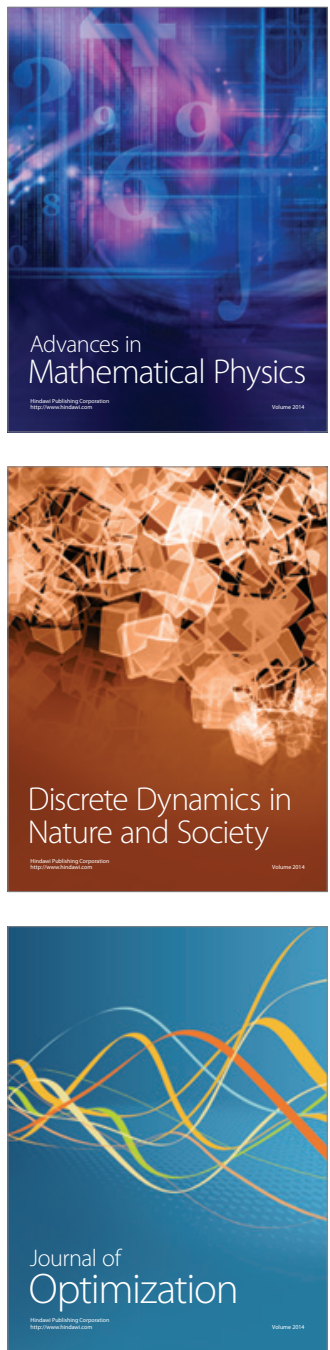